\title{
Statistical monitoring systems to inform policy decision-making, and new data sources $^{1}$
}

\author{
Susanne Schnorr-Baecker \\ Statistisches Bundesamt (Federal Statistical Office of Germany), Gustav-Stresemann-Ring 11, 65189 Wiesbaden, \\ Germany \\ E-mail: Susanne.Schnorr-Baecker@destatis.de
}

\begin{abstract}
Statistical monitoring to inform policy decision-making is becoming increasingly important at the regional, national, European and international levels such as the United Nations SDG or the German government's strategy on well-being and the good life. Both these and other policy strategies and initiatives that are more restricted in scope are increasingly being linked to statistical indicators. The majority of these indicators are provided or called for by national statistical agencies. This is because official statistics provide a guarantee of objectivity, neutrality and a scientific basis.

This article presents an overview of emerging requirements for statistical indicators, as well as applications and publications on new data sources (often referred to as Big Data) that are relevant to official statistics. Generally speaking, Big Data represent a promising data source for official statistics. Nevertheless, some challenges still have to be met before they can be mainstreamed in official statistics.
\end{abstract}

Keywords: Indicator systems to inform policy decision-making, UN SDGs, German government strategy on the quality of life, Big Data, localised data in Germany's federal statistics, regional statistics

\section{Preliminary remarks}

Statistical monitoring to inform policy decisionmaking is becoming increasingly important at the regional, national, European and international levels. Policy strategies and initiatives (both policy fieldspecific and more comprehensive) are increasingly being linked to statistical indicators. Some of these indicators are conventional and some relate to new data sources. The majority of them are provided by national statistical agencies. This is because official statistics as stipulated in the Federal Statistics Law - provide a guarantee of objectivity, neutrality and a scientific basis. They also provide reliable, high-quality informa-

\footnotetext{
${ }^{1}$ Previous publications in German in AStA Wirtsch Sozialstat Arch (2016) 10:163-185 DOI 10.1007/s11943-016-0192-2 and in English at IARIW Conference 2016 in Dresden (Germany) http:// www.iariw.org/dresden/schnorr.pdf.
}

tion on a wide variety of societal, economic and ecological phenomena and trends, often with a high degree of functional and territorial detail.

Statistical indicators can be used to operationalise policy goals, and often also to quantify them. Only the regular, objectives-oriented and target-group-appropriate monitoring of policy goals and strategies can facilitate a well founded societal discourse on the envisaged goals and their achievement through time, particularly in the case of complex and multi-dimensional strategies. Statistical indicators and their appropriate presentation also provide an important basis on which to interest, mobilise and involve citizens more closely in political decision-making processes.

The current process of defining appropriate statistical indicators at the level of the United Nations to measure progress in achieving the Sustainable Development Goals (SDGs) - the post-2015 global agenda for sustainable development that encompasses all ar- 
eas of society, the economy and the environment on an intergenerational basis) is of huge importance for official statistics worldwide. Following the adoption of the goals and targets in September $2015,{ }^{2}$ a robust system of statistical indicators (limited in number) must now also be defined that meets various criteria. First of all it must provide comparable information on global developments. Secondly it must leave sufficient space for political planning processes at the national and subnational levels.

The demand for timely, high-quality statistical indicators for a large array of real phenomena is high, and is growing continuously. It extends far beyond what official statistical agencies are currently able to offer. These agencies are called upon to seek new sources of data that entail minimum pollution burdens and damage to natural resources (see United Nations [26]). Huge potential is seen in Big Data, which is to say digitalised information that is present in large quantities and is highly mutable. ${ }^{3}$ One problem with this is that official statistical agencies, like institutions in other areas such as the private sector and academia, still possess little experience in using Big Data sources and interpreting the significance of the information they provide.

With reference to selected statistical monitoring systems used to inform policy decision-making, this article will now first of all describe the policy fields and statistical indicators that are of particular importance in Germany's federal statistics. In the subsequent section the paper will deal with new requirements, and traditional and new data sources. With reference to selected examples of statistical information based on Big Data, in the third section we will illustrate the potential that new data sources - especially Big Data - have for official statistics. Since little use has so far been made of the sources in Germany's federal statistics, this section will draw on the initial lessons learned by other institutions, particularly in the field of statistics. The article will then briefly outline the current problems associated with the use of Big Data. In the fourth and final section the paper will conclude with an overall appraisal.

\footnotetext{
${ }^{2}$ For further details see https://sustainabledevelopment.un.org/ post2015/summit.

${ }^{3}$ For a definition, see e.g. IBM [13].
}

\section{Indicator systems used in official statistics to inform policy decision-making}

\subsection{A definition of indicators}

Indicators are needed in order to better capture and describe real phenomena that due to their complexity cannot be measured directly, or whose measurement would be uneconomical. These phenomena are then rendered more susceptible to strategic control and/or management (see Schnorr Bäcker [20, p. 1]).

An indicator - the word is derived from the Latin indicare, which means 'to indicate' - is usually a measured variable that due to scientific findings, experience or convention is considered a suitable way of modelling actual facts, at least with regard to their key components and/or manifestations. This can involve single economic, ecological or social phenomena, or a combination thereof. In other words, an indicator is merely a proxy for real circumstances and is designed primarily to reduce complexity. It makes it easier to focus on particularly important real conditions.

Indicators have a long tradition in official statistics. They relate to objectively measurable facts subjective assessments, and can be expressed numerically, qualitatively or in another form (e.g. 'is present'/' is not present').

For more complex situations so-called composite indicators are used - again in order to reduce complexity. This means that a set of different (single) indicators, which in turn are aggregated into partial indicators of the composite indicator, are ultimately linked in some way (e.g. additively and with equal weighting) and combined to form an overall indicator. With regard to the aggregation of the individual indicators - particularly their weighting and the way in which they are combined - further assumptions need to be made that should reflect as closely as possible their interaction in the real world.

Often simple addition is selected, with the various components being given equal weighting. But other ways of linking the simple indicators and weighting them are conceivable. This needs to be founded on supplementary, empirically-based scientific theories or models that should be generally accepted as far as possible. In Germany's official statistics, little use has so far been made of composite indicators.

In the literature we find various criteria or considerations of practicality - presented more or less systematically - that describe the requirements which statistical indicators must meet. Essentially we can describe 
these with reference to the 'SMART' approach [28]), as called for by the UN Friends of the Chair Group (FOC) on broader measures of progress for the global Sustainable Development Goals. Indicators should be

- Specific

- Measurable

- Available/achievable in a cost effective way

- Relevant

- Timely ${ }^{4,5}$

In other words, when selecting a concrete indicator for what is usually a predetermined purpose it is important that the indicator meets the five above-mentioned criteria.

This means that the decision as to whether a particular indicator is suitable for a given purpose is based largely on practical considerations. It is important to remember this when interpreting any indicator with regard to its specific purpose and - even more so - when it is to be used as a basis for decision making.

The particular requirements concerning the nature and precision of an indicator are thus determined essentially by the specific use to which it is put.

\subsection{Selected policy fields with statistical monitoring}

The Federal Statistical Office has been supplying statistical indicators for monitoring to inform policy decision-making for a long time. Here we can distinguish between the monitoring of specific policy fields, and the cross-cutting monitoring of broader or more comprehensive areas of interest.

As the term suggests, field-specific indicator systems apply only to a particular field (e.g. a certain social group, a section of society or sector of the economy), whereas cross-cutting systems aim to capture holistically a real phenomenon or a complex policy goal, such as 'sustainability'.

Long-since established in official statistics are the short-term economic indicators that provide insights into the current status of a national economy and its trends across time $[10,11]$. These include e.g. numerical parameters such as the unemployment rate, new orders index and consumer price index, to name but a few. Subjective assessments are also conceivable, such

\footnotetext{
${ }^{4}$ The precise wording is 'available in a timely manner'; see UN Economic and Social Council [28, p. 8].

${ }^{5}$ As well as this relatively simple approach, there are also lists of detailed requirements for statistical indicators, though essentially these all include the above criteria. See e.g. Holland et al. [12].
}

as those on which the Ifo Business Climate Index are based. $^{6}$

Other examples of indicator systems for specific policy fields in Germany's official statistics provide information on the health status of the population, the life situations of people with a migrant background living in Germany, the equality of men and women in all areas of life, e.g. participation by men and women in political decision-making processes, or school education (see also [29]). Field-specific indicators are required when policymakers wish to study a segment of reality in more detail.

Increasingly, statistical indicator systems are required for comprehensive, cross-cutting policy strategies and measures, and are often being developed in close alignment with these. Cross-cutting policy strategies and indicator systems usually involved integrated approaches to topics such as sustainability, quality of life or the measurement of progress. In other words, policymakers and statisticians are increasingly attempting to move beyond purely economic or environmental trends, and capture complex societal and economic developments and their interactions as comprehensively as possible, i.e. holistically in all respects (encompassing material and geographical aspects, across time) ${ }^{7}$ Initiatives of this kind that are also especially important for Germany's federal statistics are shown in Fig. 1.

For Germany we should mention in particular the sustainability strategy laid down by the German Federal Government as early as 2002 (see German Federal Government [8]), which is reviewed at regular intervals (see German Federal Government [9]). In this connection the Federal Statistical Office regularly publishes at two-yearly intervals the Indicator Report 'Sustainable Development in Germany [5]. In addition to this, on 1 December 2014 the German Government launched a national dialogue on well-being and the quality of life entitled Gut leben in Deutschland - Was uns wichtig ist. Through largely moderated events for citizens and online responses submitted by individuals, this dialogue seeks to obtain as broad a picture as possible of citizens' ideas and aspirations concerning the good life in Germany. It is envisaged that this will bring to light deficits, and help identify policy measures to rec-

\footnotetext{
${ }^{6}$ See also e.g. http://www.cesifo-group.de/de/ifoHome/facts/ Survey-Results/Business-Climate/Calculating-the-Ifo-BusinessClimate.html.

${ }^{7}$ See Fig. 2 for details.
} 


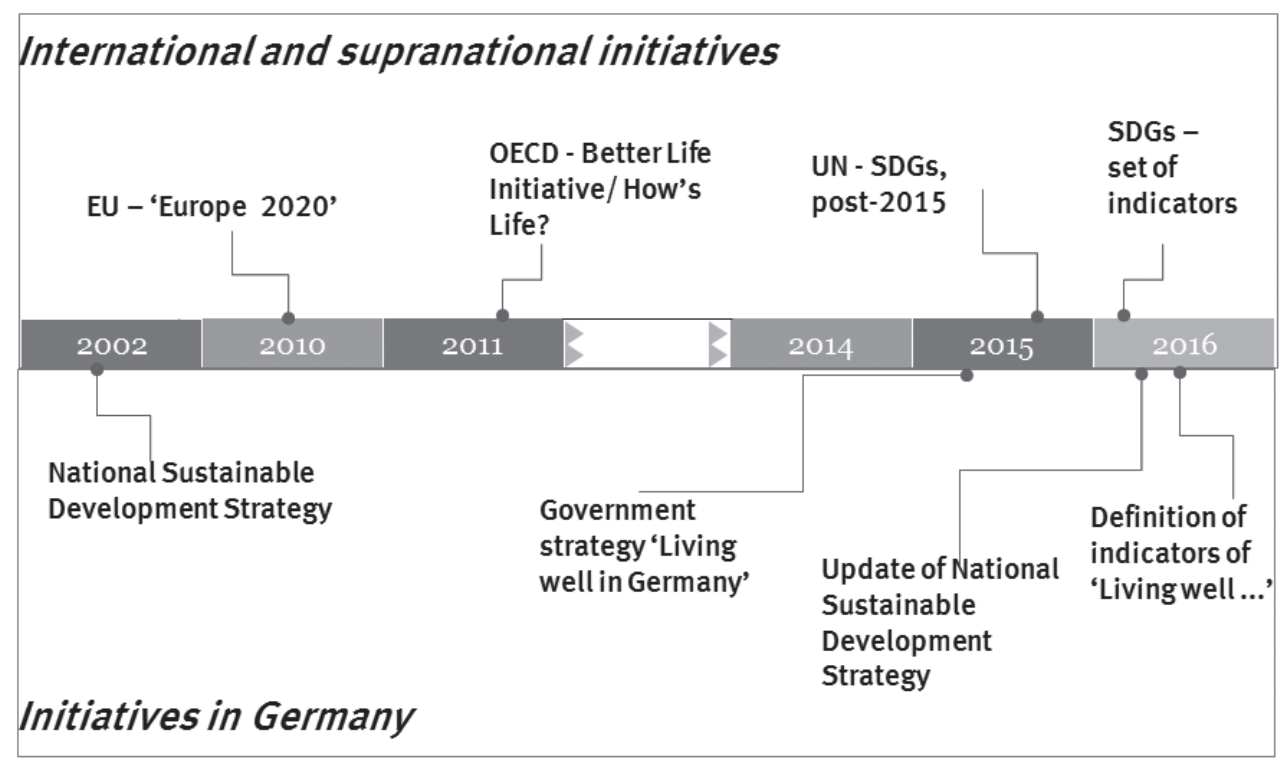

Fig. 1. Strategies for sustainable development.

tify these. ${ }^{8}$ There are also plans to develop an appropriate indicator system for this initiative so that its objectives can be better monitored and if necessary managed more efficiently as time goes on.

At the international/supranational level, the Organisation for Economic Co-operation and Development (OECD) has been studying the measurement of social progress intensively since 2004 . It has developed a corresponding system of statistical indicators. The theoretical foundations of this system were elaborated by a commission appointed by the French government in 2008 (the Stiglitz-Sen-Fitoussi Commission, named after its members), and published in a report of the same name [24]. Among other things this report provides the underpinnings of the OECD's Better Life Initiative. ${ }^{9}$ A comprehensive overview of the system of statistical indicators supporting the strategy is provided by the publication 'How's life?' [15] at the national level, i.e. at the level of the OECD member states. Since a sub-national perspective is increasingly coming to be seen as useful for efficient planning, ${ }^{10}$ the

\footnotetext{
${ }^{8}$ See https://www.gut-leben-in-deutschland.de/EN/Home/home node. $h$ tml; jsessionid=8B44491EBAB309751B1A1F40D012219D. s6t2.

${ }^{9}$ For further details see http://www.oecd.org/statistics/better-lifeinitiative.htm.

10 See e.g. United Nations: The Report of the High-Level Panel, op cit., Executive Summary or OECD [16]; for the user guide see http://www.oecdregionalwellbeing.org/assets/downloads/RegionalWell-Being-User-Guide.pdf.
}

OECD has published a paper entitled 'How's life in your region?' [16]. How the OECD's proposals can be applied on a small scale to selective autonomous municipalities in Germany - both large and small - is the subject of a work by Schnorr-Bäcker and Bömermann [21].

Especially important right now is the work being performed at the level of the United Nations concerning the broader measures of progress for the Sustainable Development Goals (SDGs) in the so-called post2015 process. ${ }^{11}$ This universally valid strategy for sustainability, which will supersede the Millennium Development Goals from 2016 onward, will also be supported by a system of statistical indicators fed with data drawn largely from official statistics. This system of indicators, which will also influence the orientation of corresponding national strategies - particularly Germany's National Sustainable Development Strategy was adopted at the $47^{\text {th }}$ Session of the United Nations Statistical Commission in spring 2016 in New York. ${ }^{12}$

Figure 2 provides an overview of important subareas captured by comprehensive systems of statistical indicators used in official statistics. Fundamental to people's quality of life are their material living conditions such as income, assets, housing situation and participation in working life. Added to this are fac-

\footnotetext{
${ }^{11}$ See https://sustainabledevelopment.un.org/.

${ }^{12}$ For further details, particularly regarding proposed possible indicators, see http://unstats.un.org/sdgs/.
} 


\begin{tabular}{|l|l|}
\hline \multicolumn{2}{|c|}{$\begin{array}{c}\text { Environmental conditions } \\
\text { Natural resources and ecosystems, climate }\end{array}$} \\
\hline \begin{tabular}{l|l|}
\hline $\begin{array}{l}\text { Material living } \\
\text { conditions } \\
\text { Income, assets, housing } \\
\text { situation, gainful } \\
\text { employment }\end{array}$ & Quality of life \\
\hline \multicolumn{1}{|c|}{$\begin{array}{l}\text { School education and } \\
\text { vocational training, } \\
\text { health, satisfaction }\end{array}$} \\
\hline \multicolumn{2}{|l|}{ Iranstitutional framework } \\
good governance, citizen participation
\end{tabular} \\
\hline
\end{tabular}

Fig. 2. Sub-areas of comprehensive sustainable development.

tors that are often referred to as general living conditions. These include school education and vocational training, health and security, as well as life satisfaction. Both the environment and the frameworks created by state institutions have a major influence on these two core areas. Environmental changes such as excessive pollution or the overexploitation of natural resources (such as air or water) for instance impact general living conditions. More recently the public sector has received more attention in the analysis of sustainability issues, because the public sector sets important enabling frameworks for business and society at large. These include the legal system, infrastructure and transfer payments of all kinds. They also include international responsibility and cooperation. ${ }^{13}$

Preliminary considerations concerning statistical monitoring for the United Nations SDGs in order to inform policy have focused on the availability of data in official statistics. They have revealed that in some cases, there are gaps in these data not only in the less developed countries, but also in highly industrialised countries. Furthermore, for various reasons (both technical and economic, and again in both types of country) data are not collected (or at least not on a timely basis) in important areas (see Osborn et al. [17]).

Dwindling resources in official statistics, a growing demand for high-quality data from official statistics and the search for new data sources are important reasons why official statistics in Germany will now have to do look more closely at issues of alternative or new data sources, and especially what are termed 'Big Data'. ${ }^{14}$

\footnotetext{
${ }^{13}$ See United Nations Sustainable Development Goals, Goals 16 and $17 \mathrm{https}$ ///sustainabledevelopment.un.org/.

${ }^{14}$ At the level of the United Nations a dedicated High Level Group for the Modernization of Official Statistics has been established. Regarding its Terms of Reference, see http://www1.unece.org/stat/plat form/display/hlgbas/HLG+Terms+of+Reference.
}

\subsection{Data sources and data quality in official statistics}

To describe in more detail the challenges that new data sources pose for official statistics, we first of all need to briefly describe the tasks and conventional approach. Official statistical agencies are permanently tasked to regularly review their programme of work, which is to say the data they supply to ensure that they match existing user needs, and where necessary to adjust them. Since the public sector, civil society, the private sector, supra- and international institutions, and ultimately each and every individual need reliable, high-quality statistical information in order to perform their respective tasks and actively participate in such processes, the official statistical agency is usually a public institution with corresponding rights and obligations. ${ }^{15}$ Here it is particularly important to mention the principle of legal legitimacy. This means that for each official statistic, a legal basis must first of all be created that usually entails an obligation to supply data. Although in the case of statistical data this involves mass phenomena in almost all instances, which are shown in an aggregated form, strict secrecy rules apply in order to protect the privacy of the respondents concerned.

New data sources, particularly Big Data, pose a particular challenge for official statistical agencies because they entail a paradigm shift in the process of generating and publishing statistical data. Traditionally, official statistics have been obtained, processed, analysed and published in accordance with the flow chart shown in Fig. 3 below.

So far, the data sources used were

(1) primary statistical surveys and

(2) secondary statistical data sources.

Whereas a primary statistical survey involves a special survey designed for a particular purpose and a specific object of investigation (usually a questionnaire, which may also be completed online), secondary statistical sources draw on the data sets of other institutions, which are usually part of the public administration system. In the latter case these data are usually closely linked to the administrative tasks performed by the institution in question. These secondary statistical data usually involve surveys that include complete data on both the people and the variables affected by the administrative tasks in question. Both can be subject to change, if the conditions of entitlement change (e.g. in

\footnotetext{
${ }^{15}$ Concerning the general framework in Germany, see the provisions of the German Federal Statistics Law (BStatG).
} 


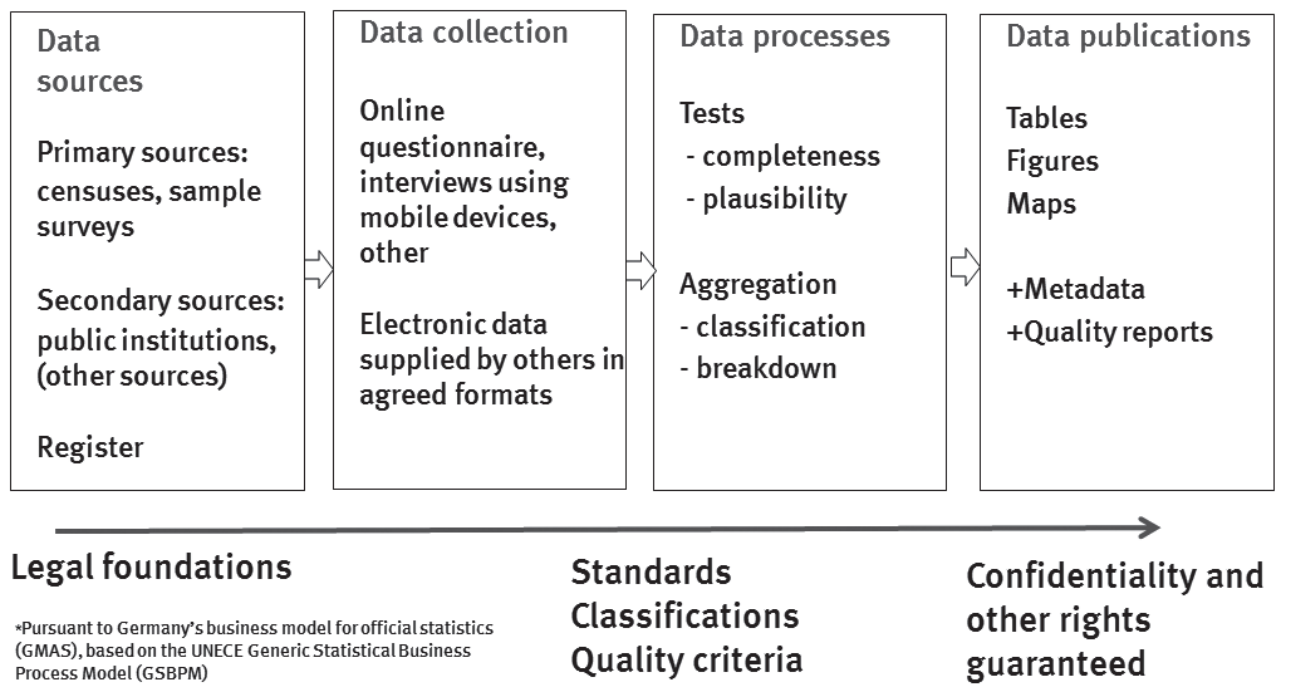

Fig. 3. The process of producing statistical data. Source: Schnorr-Bäcker [22], slide 4.

tax law or social law). This affects the comparability of the statistical data obtained, and makes it difficult to study developments across time. As far as official statistical agencies are concerned, secondary statistical data sets are to be regarded largely as a given, i.e. official statistical agencies are barely able to influence them at all.

Primary and secondary statistical data sets are wherever possible - reviewed and checked for plausibility in terms of completeness of the circle of respondents and with regard to actual content. When they are aggregated, methods, classifications and standards are applied that have often been agreed Europe-wide and worldwide, before the statistical data are published in the form of tables and visualised in the form of diagrams or maps/charts. Here both the applicable secrecy regulations and the corresponding quality standards (especially the mandate for statistics, confidentiality, efficiency, precision and reliability, validity and timeliness) ${ }^{16}$ must be considered. These processes (and sub-processes) are completed with detailed documentation not only of the results, but also the entire procedure and the quality of the data in its various dimensions.

For Big Data sources, which are not susceptible to further analysis in the conventional manner either tech-

\footnotetext{
${ }^{16}$ See Statistisches Bundesamt [6]. For the European Union see the EU Code of Practice https://www.destatis.de/DE/Methoden/Qua litaet/Leitlinien/Verhaltenskodex.pdf?_blob=publicationFile, or for the UN fundamental principles see http://unstats.un.org/unsd/dnss/ gp/fundprinciples.aspx.
}

nically or methodologically (at least in their pure form of mass data in electronic form with a large degree of variability in terms of content and time frame), the starting point becomes a different one. Here, for a given data set specially developed methods and procedures are applied to search for certain patterns and structures, which need to be specified and categorised with respect to the real phenomena that are of interest. Results obtained in this way need to be studied carefully with respect to the findings and conclusions to be drawn from them, especially with respect to possible disruptive factors that might falsify results, before they can be used as a basis for practical decision-making and planning activities.

'Big Data' is a generic term that can refer to a whole range of different data sources for use by official statistical agencies (e.g. online publications and applications such as websites or theme-based supply and/or demand portals, various channels of communication whether individual or involving social networks, machine- or process-generated sensor data, or satellite images). Consequently, the appropriate procedure must be defined on a case-by-case basis.

In a relatively small number of cases, in which variables are relatively homogenous and limited, and data generation processes easy to understand, the processes associated with the extraction of results and the assessment of their quality would appear to be less complex. According to the present status of the debate on the use of Big Data in official statistics, the spectrum of their possible uses ranges from entirely novel applications to processes that resemble the use of secondary statistical data sources. 
Nor is it possible at present to say anything specific about data quality or criteria. The benefits of using Big Data sources are seen as their timeliness and their potential to ease burdens. Furthermore, using them - at least in the medium and long-term - is likely to be efficient, assuming we disregard the initial investment required as well as any ongoing costs for the supply of the original material. All other factors such as precision and reliability, data protection and data access will need to be assessed on a case-by-case basis. It is also questionable whether the processes, procedures and methods, as well as standards and classifications, which have been largely harmonised within official statistics can still be used for these new data sources without modification. It is to be anticipated that corresponding innovations will need to be introduced here, and that modifications and adjustments will need to be made in order to solve the problems that arise.

\section{Big Data - new data sources for statistical indicators}

Official statistical agencies are experiencing an increasing demand for current statistical evidence from various user groups. At the same time the resources available to them are declining, for reasons that will be not be discussed further here.

In the search for new data sources as a permanent task of Germany's official statistical agency, the focus has already shifted in recent decades. Whereas originally primary statistical surveys were used predominantly, today almost half of Germany's federal statistics are based on secondary statistical sources. Increasingly, the proliferation of online applications and offerings as well as digital networks in all areas of life and the economy mean that new sources of 'Big Data' are becoming available. ${ }^{17}$ Their potential is seen chiefly in the fact that they

- enable the supply of supplementary information on existing statistics

- replace existing statistics - at least in certain areas

- supply entirely new types of statistical evidence.

Although work with Big Data in Germany's federal statistics is still in its infancy, the Federal Statistical Office has been engaging with this issue intensively for a long time in various bodies at the European and international levels (see Schnorr Bäcker [22]).

\footnotetext{
${ }^{17}$ An overview of the pilot studies that currently exist worldwide for official statistics is provided by the UNECE website: http://www1.unece.org/stat/platform/display/BDI/UNECE+Big+ Data+Inventory+Home.
}

\subsection{Mobile phone data for population, tourism and traffic statistics}

We will now briefly present selected Big Data sources and their use in official statistics. With particular reference to the various areas of activity that fall under 'sustainability', we will first of all outline the potential that exists and where the limits are believed to lie; we will also briefly deal with the technical aspects, to the extent that this facilitates understanding. The selection of examples presented is based on the sources considered to have the highest priority for official statistics at the international and European levels [31].

The work performed on the use of mobile phone network data in official statistics in various statistical offices, particularly in the European Union (see e.g. Ahas [1], Saluveer and Ahas [18] and Tiru [25]), is relatively advanced. ${ }^{18}$ Based on these data it is possible first of all to draw relatively timely conclusions concerning the actual locations and movement flows of the population within a small area (see Jonge et al. [14]), if we assume that the vast majority of the population possess a mobile phone device. Secondly, roaming data provide current information on foreigners in a specific country or region or at a certain location (see Fig. 4), provided that the distortions associated with that, e.g. resulting from the use by individuals of more than one mobile phone for professional and/or private purposes, can be identified and eliminated.

So far, statistics on population by day from a single data source have not been published in official statistics. The Federal Statistical Office publishes information on the population officially registered with the various municipalities in Germany. Barely any information is available on their spatial distribution in any dynamic sense. This so-called population by day can be approximated at best by aggregating various individual statistics (e.g. employees liable for social security contributions at the place of work, school students, people in the health care system in the municipality), provided that we disregard methodological differences (e.g. concerning definitions, possible cut-off thresholds, different periodicities and periods/days of survey).

\footnotetext{
${ }^{18}$ The work performed in Estonia would appear to be the mos advanced. Concerning the various possible applications of mobile phone network data, see for instance the work of Statistics Netherlands: http://www.cbs.n1/NR/rdonlyres/4EDB51ED-927A-4A69-B8 F3-/4DC57A44DDE4/0/Timepatternsgeospatialclusteringandmobil itystatistics.pdf.
} 


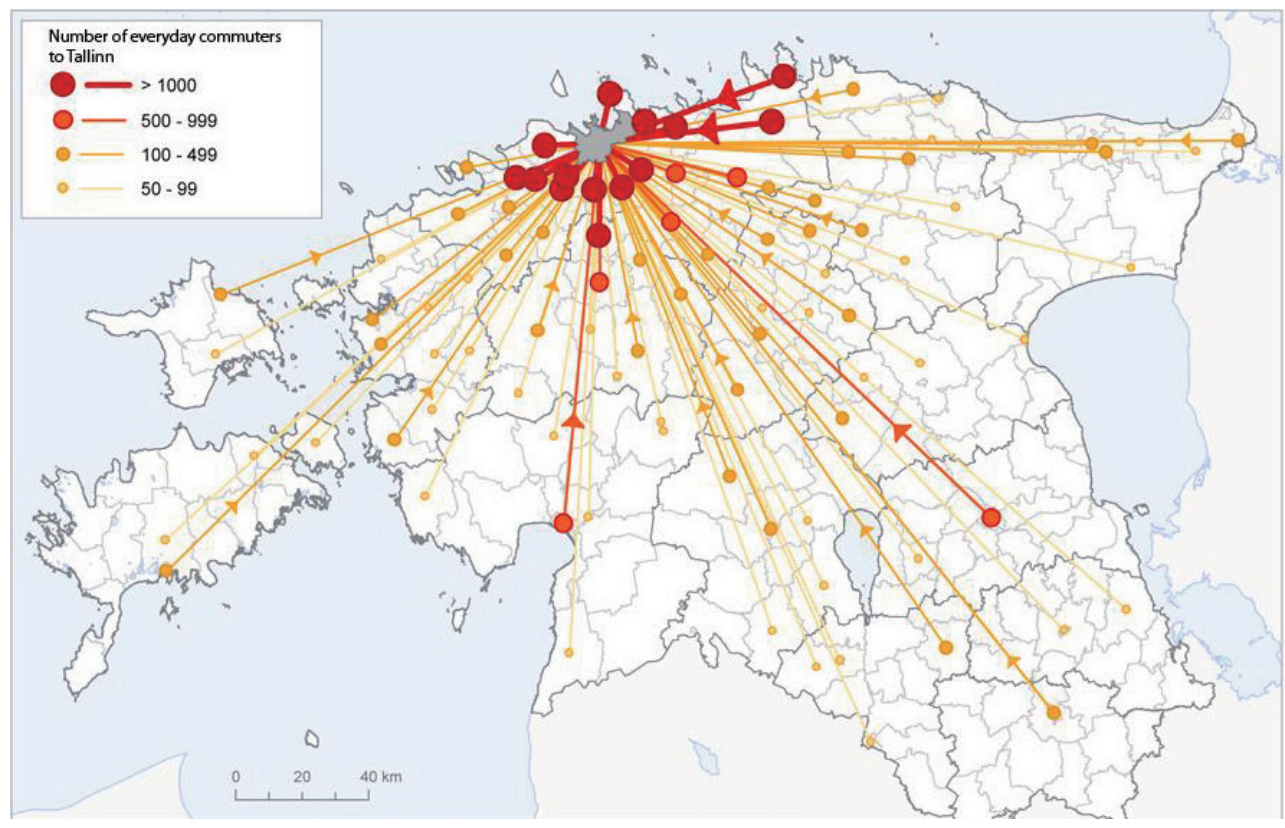

Fig. 4. Population by day based on mobile phone data. Source: Tiru [25, p. 14].

Localised statistics that provide data on geospatial interrelationships and population by day are urgently required for various planning projects and to determine their impacts on 'sustainable development' and/or the quality of life of each individual. The goal would be to establish balanced relationships between urban and rural areas, particularly to compensate the respective disadvantages. Examples we could mention include high rents and little open space in urban areas. This contrasts with the relatively high transaction costs and times for journeys to work, errands of all kinds and less diverse offering of goods and services in rural areas. Localised statistics are important, not only in terms of equal living conditions ${ }^{19}$ or balancing out living conditions in various regions. ${ }^{20}$ They would also be helpful for numerous other purposes such as disaster risk management, forward-looking urban planning ${ }^{21}-$ also

\footnotetext{
${ }^{19}$ Concerning the provisions of Article 72 of Germany's Basic Law, see http://dejure.org/gesetze/GG/72.html.

20 For the European Union, see the Consolidated Version of the Treaty on European Union and the Consolidated Version of the Treaty on the Functioning of the European Union 2010/C $83 / 01$, Article 14 '...promoting social and territorial cohesion... http://eur-lex.europa.eu/legal-content/EN/TXT/PDF/?uri=OJ: C:2010:083:FULL\&from=EN.

${ }^{21}$ Concerning the points raised at the level of the United Nations presented in the UNIVERSAL SUSTAINABLE DEVELOPMENT GOALS, see Goal 11 - Resilient Cities: https://sustainabledevelop ment.un.org/post2015/summit.
}

with a view to demographic change - or developing rural areas.

Mobile phone data not only provide information on the catchment area of a region or city, they also provide some indication of the intensity of traffic flows. Furthermore they can provide a basis for estimating transaction times, i.e. they provide information on the way individuals spend their time. Information of this kind may also be important for assessing the quality of life as well as environmental issues (such as noise and pollutants).

Moreover, roaming data can supply timely information on foreign tourists in a given region (see Fig. 5).

For regions whose main source of revenue is tourism, timely data that enable them to assess the potential and current occupancy rates are likely to be more suitable than data from primary statistical surveys, which are usually only available after a certain time lag. Statistical information based on mobile phone data can also be used in various ways to assess 'sustainable development' and the quality of life. For tourism regions they not only provide current information on the gainful employment and income of the population living and working in the region; when capacity utilisation levels are higher they also highlight possible ecological problems (e.g. the generation of solid waste, energy requirement etc.).

Other studies are using mobile phone data (among other sources) to explore new business models for the 


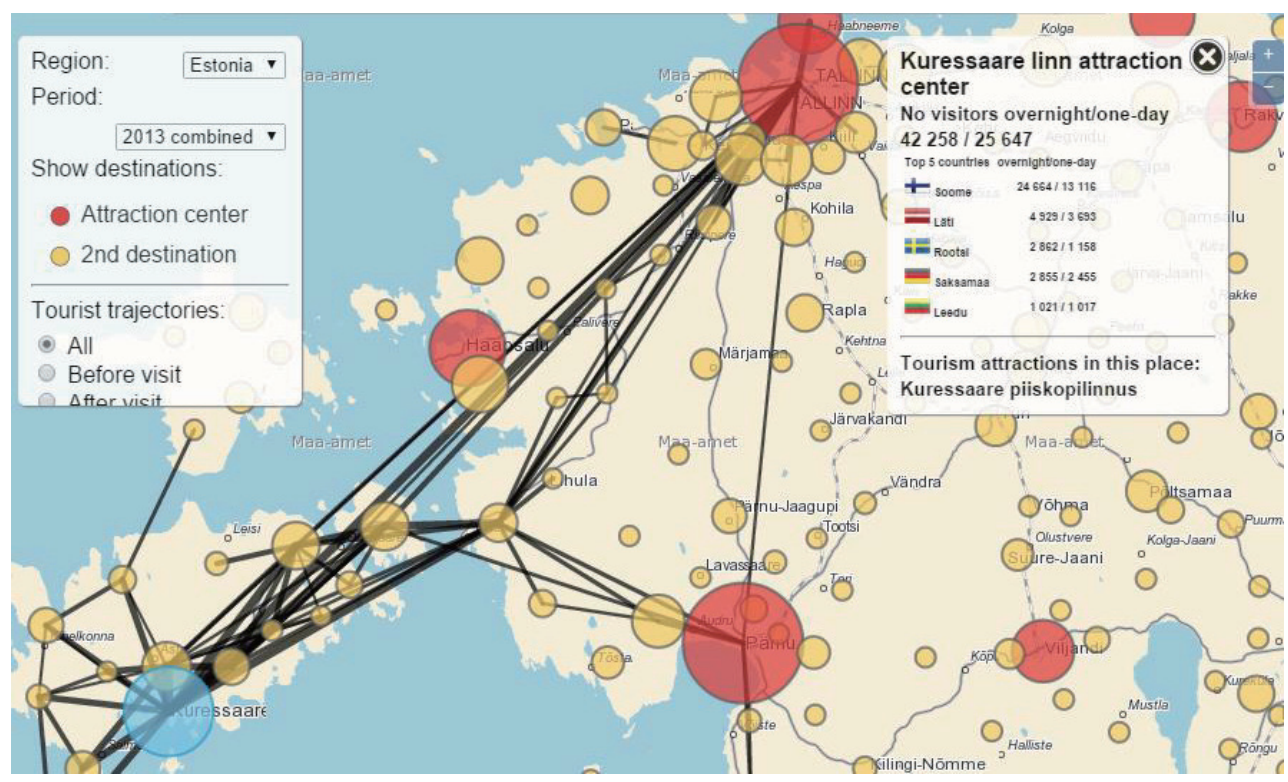

Fig. 5. Foreign tourists, determined using mobile phone data. Source: Tiru [25, p. 13].

digital economy. These include means of transport, e.g. cars, which are made available to private individuals or businesses on demand, often in return for payment.

One example of this is car sharing and its importance for urban mobility. Using smartphone apps it is relatively easy and quick to hire cars for individual purposes, especially in inner city areas. Data of this kind could also use for statistical purposes. For further details see for instance a study by civity [4]. Although the economic importance of car sharing is still relatively low, at least in Germany, peer-to-peer services forming part of the sharing economy constitute new business models. This is also the case in other sectors, such as the short-term and temporary renting out of living space, which competes with the hotel industry. So far, these models have probably been barely recorded at all in official statistics. Whether and how such new business models affect the economy itself, employment or income generation at both the micro- and macroeconomic levels, are issues that have been under discussion for a long time, particularly within the OECD. ${ }^{22}$

Since official statistical agencies still have relatively little experience with using mobile phone data, it is not yet possible to make any specific statements concerning their actual uses.

\footnotetext{
${ }^{22}$ See among others the work of the OECD on this topic, e.g. http://oecdinsights.org/2014/12/22/what-is-a-taxi-regulation-andthe-sharing-economy/.
}

Everyone agrees that accessing data from mobile phone networks presents a major challenge from a legal, administrative and economic perspective. Issues of data access, data protection and the costs of data use are particularly important in this context. Appropriate technical and methodological solutions will also need to be found to deal with the different forms and ways in which the data are kept, which are usually networkspecific (see Tiru [25]).

\subsection{Satellite images for environmental statistics - the example of concentrations of fine particulate matter}

Continuous monitoring by satellites can be an important source of data, not just for official statistics. Satellite images offer the possibility of comprehensive information. They are an important basis for localised statistical data, for which only limited data are currently available in Germany's federal statistics, partly because of the costs.

We will now outline an approach pursued by OECD to determining atmospheric concentrations of fine particulate matter in selected cities of OECD member states using satellite images.

Atmospheric concentrations of fine particulate matter are closely linked to industrial production, urbanisation and traffic. They involve various deleterious impacts. Atmospheric pollutants were quickly linked to selected diseases of the respiratory tract. Ecosystems 


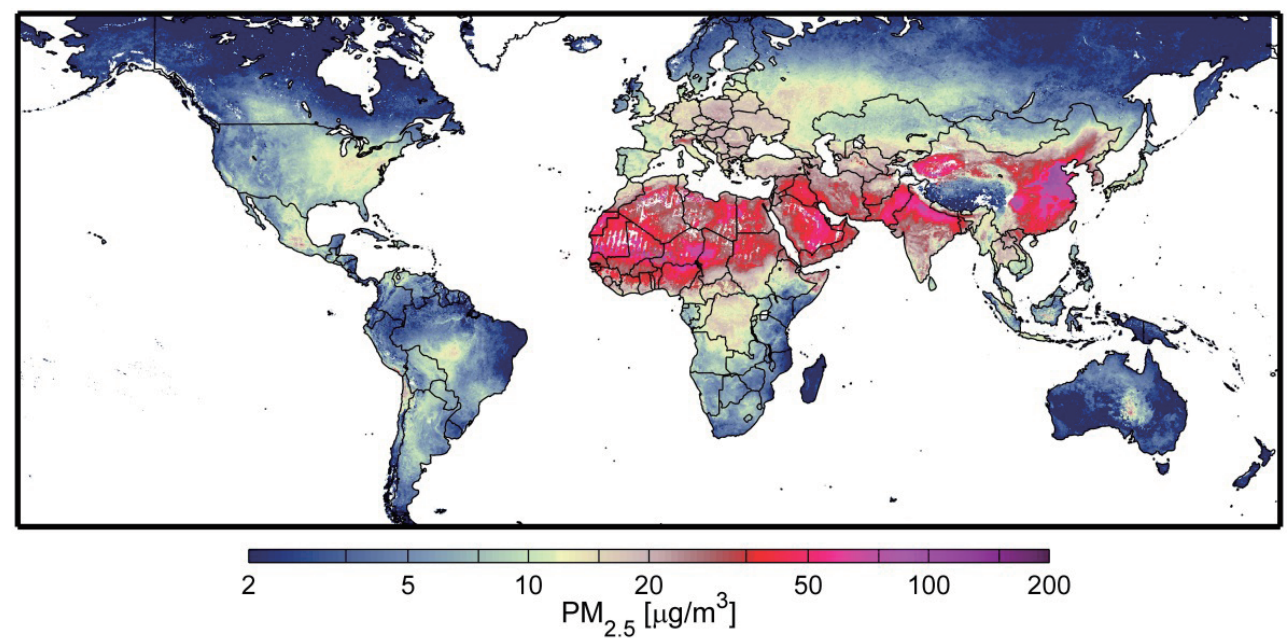

Fig. 6. Atmospheric concentrations of fine particulate matter (PM 2.5) based on satellite images. Source: Van Donkelaar et al. [30, p. 138].

and species diversity can also be disrupted by airborne pollutants. These negative effects can be all the more severe, the greater the pollution burden. Consequently, 'atmospheric pollution' is an important indicator of 'quality of life' in Germany's strategy for sustainability [5, p. 44].

Traditionally, pollution is measured using measuring stations that have been set up at specific locations. This means that the values are recorded directly, offering the possibility of direct monitoring over a long period of time. Different kinds of pollutant can also be measured. Given the various instruments and methods used for measurement, and the selection of sites, the values measured are limited to these specific locations. This means that standardised, exhaustive and transboundary monitoring of atmospheric pollutants is barely feasible. Satellite images, on the other hand, permit the global observation of fine particulate matter concentrations using standardised methods and for selected agglomerations (e.g. cities, regions or countries). They also allow for long time series' (see Brezzi and Sanchez-Serra [2]). Van Donkelaar et al. [30]) have developed an approach for comprehensively analysing satellite images in conjunction with annual observed values for atmospheric concentrations of fine particulate matter (PM 2.5) measured at measuring stations on the ground. To obtain results that were as stable and certain as possible they conducted the analysis over an extended period (1998-2012) (see Fig. 6). They stored the fine particulate matter values they obtained in this way in a grid with cells of one square kilometre, for further analysis.

The further analyses performed by von Brezzi and Sanchez-Serra [2], particularly the identification of sta- tistical indicators, were based on these results. ${ }^{23}$ They show how the fine particulate matter values obtained using the method of van Donkelaar et al. [30]) can be linked to densely populated areas. From this they calculate not only the mean concentrations of fine particulate matter for each of their member states (in this case for the period 2002-2011). They also calculate the minimum and maximum burdens at the sub-national level, i.e. for cities and/or regions for each OECD member country. In principle this would be possible for all zones in a country.

For statistics at the sub-national level, such as those for the SDGs of the United Nations, ${ }^{24}$ satellite images could be an important source of data. We may assume that by combining analyses of different data sources both traditional and new - it will be possible to gain more penetrating insights into complex structures and trends, e.g. with regard to settlement behaviour. In contrast to directly measured values, which provide significant information only with respect to specific points in time, this combined approach offers the possibility using appropriate methods to generate methodologically comparable time series for extremely small territorial units, also for several periods, provided that reliable empirically determined reference values are available.

\footnotetext{
${ }^{23}$ For their study, Brezzi and Sanchez-Serra [2] used the working paper by van Donkelaar et al. [30]), which had already been published in 2014; see Brezzi and Sanchez-Serra [2, p. 4].

${ }^{24}$ See the UN General Assembly [27]). Under various goals, this report lists targets that require cooperation at the local level, as for instance under Goals 6 (water and sanitation), 8 (growth and employment), 11 (resilient cities), 12 (sustainable consumption and pro-
} 


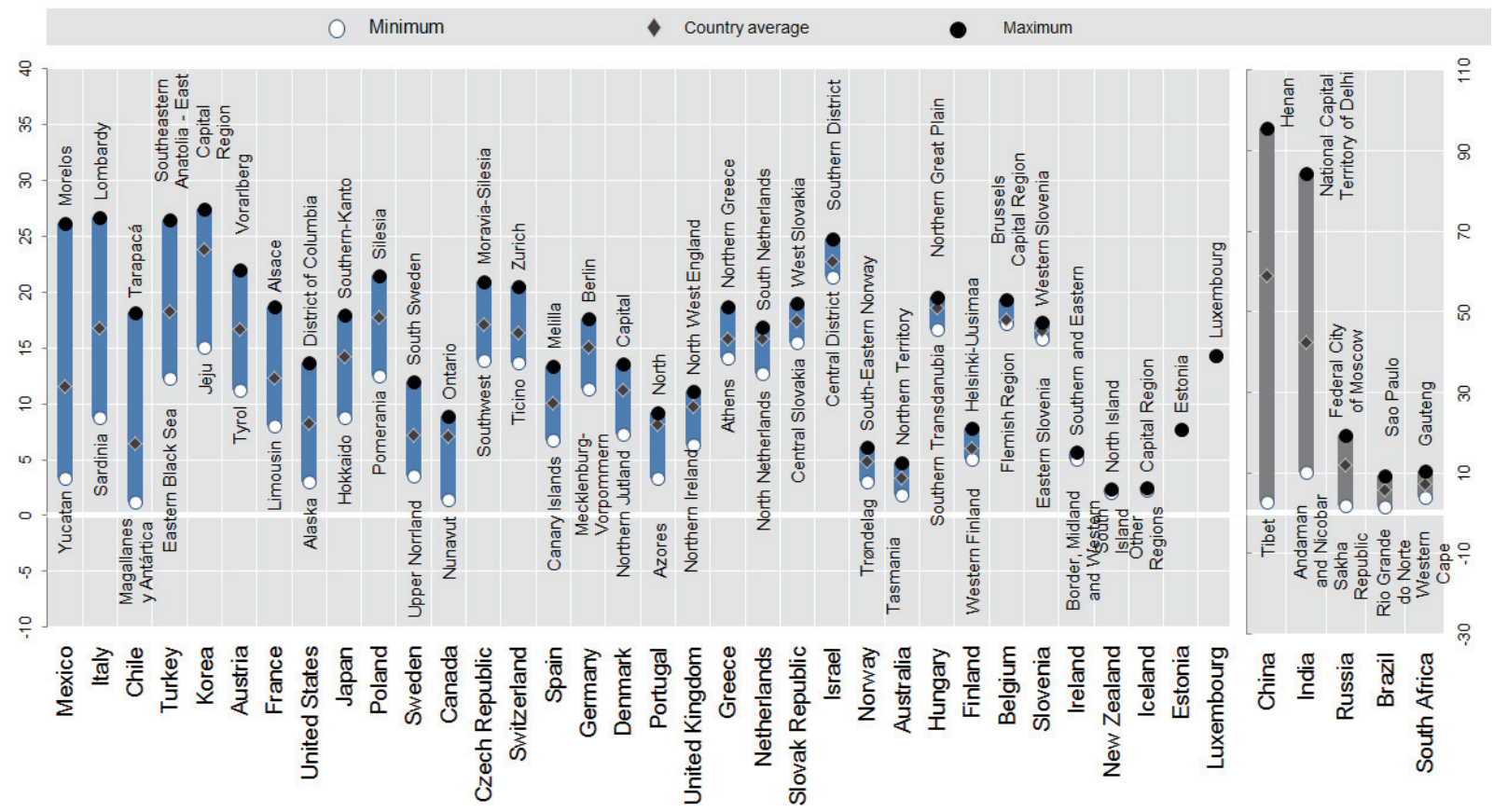

Fig. 7. Regional differences in atmospheric concentrations of fine particulate matter for the OECD member states. Source: Brezzi and Sanchez-Serra [2, p. 10].

Studies of this kind (for which grid data are also helpful) would also be possible for Germany's federal statistics. Due to an amendment of the Federal Statistics Law dated 1 August 2013, now grid cells of $100 \mathrm{~m}$ $\times 100 \mathrm{~m}$ may be used in federal statistics, subject to the applicable data protection rules. For the two censuses conducted in Germany recently, the agricultural census in 2010 and the population census in 2011, interactive online applications for grid data were developed; ${ }^{25}$ these are freely accessible to the general public. The census atlas in particular presents selected indicators on population data (chiefly population density), as well as other indicators, also at the sub-municipal level in the form of grids.

Grid data are an important basis for demarcating and typifying spatial units [23], e.g. with respect to 'rural' or 'urban' and for classifying towns and cities of different orders of magnitude (ranging from metropolises, to urbanised areas, to urban cores). A distinction of this kind is helpful for highly specific and localised analy-

duction patterns), 13 (combating climate change) and 15 (terrestrial ecosystems).

${ }^{25}$ For the census atlas see https://atlas.zensus2011.de/ and for the agricultural statistics atlas see http://www.atlas-agrarstatistik.nrw. de/. ses involving sustainable development, and the analysis of satellite images. Satellite images are used when there is no other way of capturing life-threatening phenomena such as extreme weather events and their impacts on the population. ${ }^{26}$ At present, issues of access as well as costs are still likely to preclude a broader use of satellite images. Interpreting them also requires suitable empirical reference values, and corresponding methods for comprehensive analyses also need to be identified.

\subsection{Tweets for health statistics}

Social networks, and the opinions, assessments, experiences and information they express, are a major source for various topics. Among other things they can be used to capture statistically public perceptions of health issues - an important aspect of the quality of life. ${ }^{27}$ With reference to an example of data from Twit-

\footnotetext{
${ }^{26}$ See e.g. the NASA website http://www.nasa.gov/topics/earth/ haiti_nasa.html.

${ }^{27}$ High-quality statistical information of this kind is increasingly being requested from official statistical agencies, as is the case for the Sustainable Development Goals of the United Nations. First examples of this are the European survey EU-SILC, and for Germany Leben in Europa. See https://www.destatis.de/DE/ Meta/AbisZ/EU_Silc.html.
} 
ter, we will now briefly discuss the potential that this kind of Big Data can have.

Chew and Eysenbach [3] conducted an analysis of tweets on the topic of 'swine flu' or H1N1. Their aim was to develop a suitable approach for this Big Data source, and identify its importance for specific issues. The study included tweets made in the period from 1 May to 31 December 2009. During this period the proportion of tweets containing terms such as $\mathrm{H} 1 \mathrm{~N} 1$ or swine flu rose from $8.8 \%$ o $40.5 \%$ [3].

Disregarding the issue of access to these data, the method can be outlined as follows. From the huge number of tweets, Chew and Eysenbach [3] first of all extracted those relevant to the topic and categorised the content (e.g. whether it involved personal experiences, personal opinions or publicity). In a next step they encoded the content as well as other symbols contained in the tweets such as emoticons and information such as links on a qualitative basis (e.g. concern, frustration). They manually analysed a total of 5,395 tweets - a random sample, as it were - for the period under consideration, and investigated their relevance to the issues, and tested this against an automated analysis of all tweets relevant to the issues over the same period. This enabled them to show (see Fig. 8) which issues were of particular interest to the public during the period under investigation. They were also able to demonstrate that certain spikes were closely linked to measures such as warnings, particular those issued by the World Health Organization (WHO).

So far, official statistical agencies have provided chiefly objectively verifiable information on the health status of the population. This includes reportable diseases, with the figures reflecting the number of cases where a corresponding diagnosis has been made and the disease reported. Using data supplied by official statistical agencies, impact assessments can at best be performed only implicitly and indirectly. Using analyses like those performed by Chew and Eysenbach, it would be possible to obtain - in addition to objectively observable facts - information on whether and how phenomena and their effects, particularly those that negatively impact the quality of life, are being perceived by individuals subjectively. It would also be possible to determine whether measures designed to redress problems or improve the current situation were having the desired effect. Further studies will need to show whether and to what extent information from social networks can actually supply high-quality, reliable statistical evidence for indicators. ${ }^{28}$ It is conceivable, for instance, that sampling bias or poor representativity may pose particular challenges with data from social networks.

\subsection{Crowdsourcing to determine the quality of public services}

Essentially, crowdsourcing is based on individuals using their activities and observations to support certain real phenomena more effectively through the Internet. The actual phenomena can vary widely, as the following examples show. Increasingly, one key determining factor for sustainable development, ${ }^{29}$ and thus also for growth and employment, is believed to be the quality of our satisfaction with the public administration in the broadest sense. This can contribute directly or indirectly to the well-being of individuals, and thus to the well-being of those sections of the population that use the services. It can also contribute toward economic efficiency.

Germany's federal statistics are increasingly reflecting this aspect of sustainable development. In 2015, on behalf of the German government the Federal Statistical Office surveyed citizens and businesses regarding their satisfaction with public services, particularly with respect to the 'Better legislation 2014' programme [7]. This was based on a so-called life situation model defined initially through preliminary studies conducted at the Federal Statistical Office and a representative survey of 1,000 people; the data for this were obtained from conventional surveys [19].

The government of Latvia chose another approach. It developed a 'football' smartphone app in close cooperation with the European Union's European Public Administration Network (EUPAN), in order to improve the user-friendliness of public institutions. ${ }^{30}$ The app enables the user of a public institution to provide immediate feedback on the quality of processes, cooperation etc.; it also contains the relevant contact details. It is used to collect data, which are then processed

\footnotetext{
28 In another study conducted by Global Pulse, a research network of the United Nations, Twitter data were used to draw conclusions concerning price trends in Indonesia; see http://www.unglobalpulse. $\mathrm{org} /$ social-media-social-protection-indonesia.

${ }^{29}$ See the UN General Assembly [27], Goal 16.

${ }^{30}$ See the websites http://www.eupan.eu/files/repository/201503 23135931_Football_Pass_To_Get_A_Better_Result.pdf https:// prezi.com/rrffitnqppjm/crowdsourcing-for-better-public-servicesin-latvia/ or http://www.eupan.eu/en/documents/show/\&tid=902.
} 


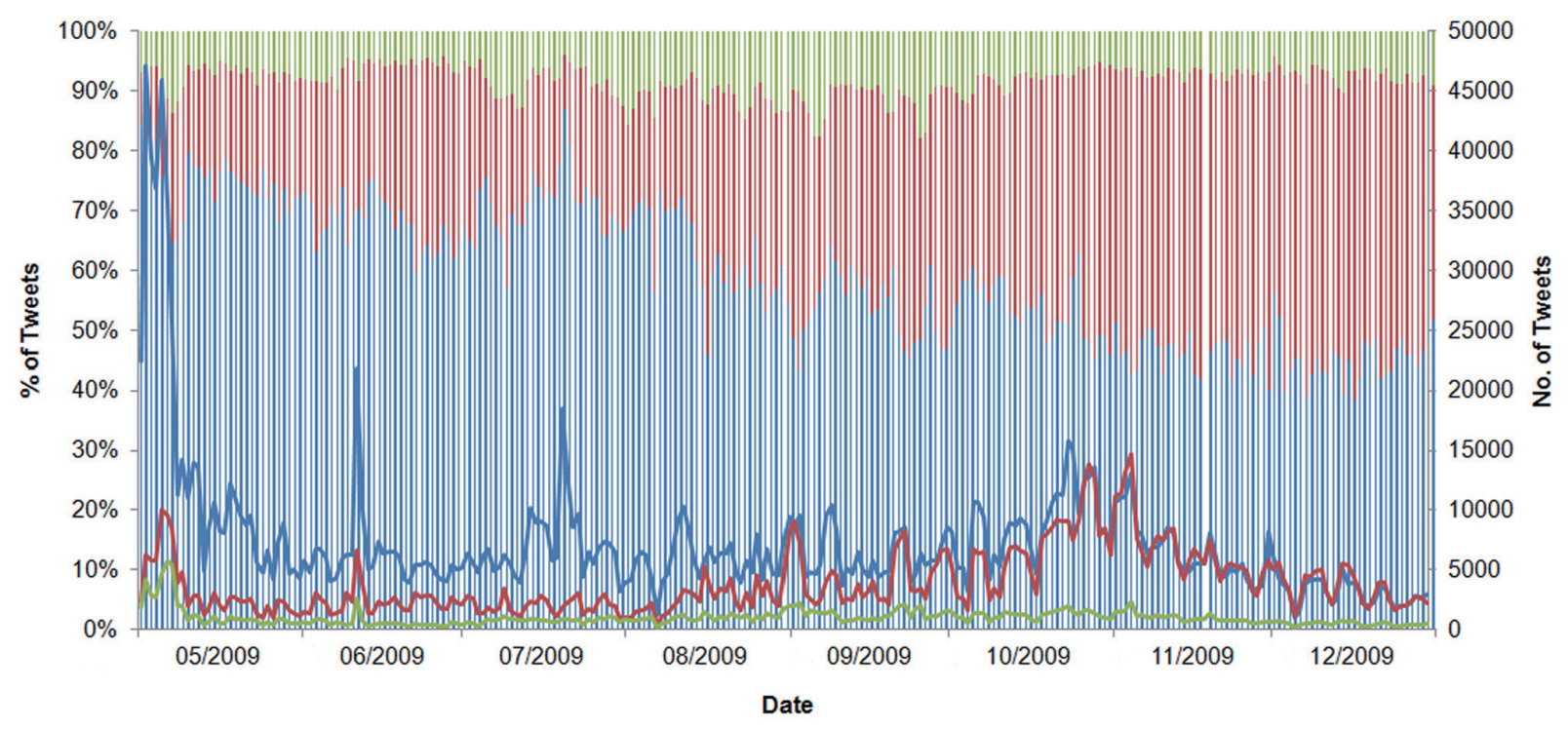

Fig. 8. Tweets (absolute and relative figures) on H1N1 (swine flu) from May to December 2009. Source: Chew and Eysenbach [3, p. 2].

and analysed for corresponding reports produced at the government level.

This example shows that new methods of obtaining data in the form of crowdsourcing are being used. The data sets obtained can also be used for statistical analyses. There are also similar applications in areas outside of official statistics, e.g. for obtaining information to protect selected bird species. ${ }^{31}$ Here it would be possible to realise the bird index called for in monitoring systems to support policy decision-making. ${ }^{32}$ These use not only innovative, but also in many cases traditional survey methods that differ from other traditional approaches basically only in the nature of the medium, assuming we disregard the modifications to content made to suit the media in question. ${ }^{33}$

With this kind of Big Data source, the key question that arises concerns representativity. In official statistics, representativity means that the real facts to be

\footnotetext{
${ }^{31}$ For example, Germany's Nature and Biodiversity Conservation Union regularly calls for birds to be counted; see https://www.nabu. de/tiere-und-pflanzen/aktionen-und-projekte/stunde-der-gartenvoeg $\mathrm{el} /$.

${ }^{32}$ See also the proposals of the German Council of Economic Experts together with the Conseil d'Analyse Economique: Wirtschaftsleistung, Lebensqualität und Nachhaltigkeit: Ein umfassendes Indikatorensystem, an expert report commissioned by the FrancoGerman Council of Ministers, December 2010, Paderborn, published in January 2011, p. 24 http://www.sachverstaendigenrat-wirtschaft de/fileadmin/dateiablage/Expertisen/2010/ex10_de.pdf.

${ }^{33} \mathrm{See}$ for instance the questionnaire at https://www.nabu.de/imper $\mathrm{ia} / \mathrm{md} /$ content/nabude/vogelschutz/stundedergartenvoegel/nabu-stun de-der-gartenvoegel2015-zaehlhilfe.pdf.
}

captured appropriately reflect the relevant statistical population with its respective sub-populations/strata. Whether or not that is the case with an app of this kind, is an open question. First of all we must assume that only those individuals respond who are actually affected, rather than those who might also be potentially affected. Secondly there is a risk that groups which are satisfied with the services of an institution are underrepresented, because they do not use the app to express their satisfaction, e.g. for reasons of convenience. Disregarding a lack of representativity, a method of this kind can de facto lead to the desired improvements, provided that the number of respondents (in this case 'satisfied individuals') is considered sufficient.

\section{Looking ahead}

The progressive digitalisation of numerous areas of life and the economy is bringing forth a large number of various new data sources. It remains to be seen whether all of them will involve very large quantities of data. Furthermore, whether or not these will always require fundamentally new methods or modes of cooperation etc., or whether at least some of them can be used with minor modifications to existing procedures and methods, are questions that further studies will need to answer.

The present paper is a response to the growing demand for high-quality indicators from official statistics on new areas and issues of interest, for more timely 
data and for more efficient statistical production methods to support monitoring and inform policy decisionmaking. Against this background, the paper presented selected pilot studies on various examples of new data sources and their use for selected indicators applied in official statistics on sustainable development.

The path taken of studying step by step and in detail the relevance of new data sources for official statistics should be continued for two reasons. First of all, by using new data sources it may be possible to obtain statistical information that has either not been previously available at all in official statistics, or has been inadequate, such as information on population by day. Secondly, it may be possible to obtain supplementary information on existing statistics that e.g. permit impact assessments. There is also a need for further investigation to determine whether high-quality data can be obtained from Big Data sources that meet the standards of official statistics. The costs associated with this should be carefully weighed against the possible benefits. This assessment should also take into account the risks associated with incorrect decisions taken on the basis of insufficient data quality or availability. These considerations must be applied in each individual case, i.e. to each item of statistical information or each statistical indicator derived from a new Big Data source, based on the existing quality criteria.

In the past, official statistical agencies have regularly made adjustments to new methods and approaches, once these have proved enduring and reliable. Examples from the recent past include the growing use of data from public institutions, and the processing and visualisation of highly localised statistical data in the form of grids. Whether and to what extent Big Data sources (and if so which ones) can be used for official statistics - particularly in conjunction with statistical indicators to support policy decision-making at the national, sub-national and international/supranational levels, will need to be demonstrated by carefully evaluating specific applications.

\section{References}

[1] R. Ahas et al., Using mobile positioning data to model locations meaningful to users of mobile phones, Journal of Urban Technology 17(1) (2010), 3-27.

[2] M. Brezzi and D. Sanchez-Serra, Breathing the Same Air? Measuring Air Pollution in Cities and Regions, OECD Regional Development Working Papers, 2014/11, OECD Publishing. http://dx.doi.org/10.1787/5jxrb7rkxf21-en. Accessed on 4 May 2016, 2014.
[3] C. Chew and G. Eysenbach, Pandemics in the age of Twitter: content analysis of Tweets during the 2009 H1N1 outbreak. PloS one 5.11: e14118. https://tspace.library.utoronto.ca/bitst ream/1807/25454/1/Chew_Cynthia_M_201011_MSc_thesis. pdf. Accessed on 4 May 2016, 2010.

[4] Civity, Urbane Mobilität im Umbruch, civity Management Consultants, matters no.1: Berlin. http://matters.civity.de/. Accessed on 4 May 2016, 2014.

[5] Federal Statistical Office, Sustainable Development in Germany, Wiesbaden, October 2014, 44-45.

[6] Federal Statistical Office, Strategie- und Programmplan, Für die Jahre 2015 bis 2019, Wiesbaden, June 2015, 13 ff, 2015.

[7] Federal Statistical Office, Zufriedenheit der Bürgerinnen und Bürger in Deutschland mit behördlichen Dienstleistungen Ausgewählte Ergebnisse der Zufriedenheitsbefragung 2015, Wiesbaden, August 2015, 2015.

[8] German Federal Government, Perspectives for Germany Our Strategy for Sustainable Development, 2002. https:// www.bundesregierung.de/Content/EN/StatischeSeiten/Schw erpunkte/Nachhaltigkeit/Anlagen/perspektives-for-germanylangfassung.pdf?_blob=publicationFile $\& v=1$. Accessed on 17 June 2016, 2002.

[9] German Federal Government, National Sustainable Development Strategy, 2012 Progress Report. http://www.bundesregi erung.de/Content/DE/_Anlagen/Nachhaltigkeit-wiederherge stellt/2012-06-07-fortschrittsbericht-2012-englisch-barrieref rei.pdf?_blob=publicationFile. Accessed on 17 June 2016, 2012.

[10] U. Heilemann and S. Schnorr-Bäcker, Rezession 2008/09 in Deutschland: War sie vorhersehbar? Presentation at the German Statistical Week on 17 September 2013 in Berlin, 2013.

[11] Heilemann, Ullrich/Schnorr-Bäcker, Susanne, Could the start of the German recession 2008-2009 have been foreseen? Evidence from real-time data, RPF Working Paper No. 2016003, February 16, 2016, Research Program on Forecasting, Center of Economic Research, The George Washington University, Washington DC: https://cer.columbian.gwu.edu/sites/ cer.columbian.gwu.edu/files/downloads/2016-003.pdf. Accessed on 17 June 2016.

[12] J. Holland et al., Measuring change and results in voice and accountability. DFID Department of International Development, United Kingdom, Working paper 34, December 2009.

[13] IBM, The four V's of Big Data. IBM Big Data Hub Infografik. http://www.ibmbigdatahub.com/sites/default/files/infographic _file/4-Vs-of-big-data.jpg?cm_mc_uid=85033156291614454 $204167 \&$ cm_mc_sid_50200000 $=1445420501$. Accessed on 4 May 2016, 2014.

[14] E. Jonge et al., Time patterns, geospatial clustering and mobility statistics based on mobile phone network data. Statistics Netherlands, Discussion Paper 2012, The Hague/Heerlen, 2012.

[15] OECD, How's Life - Measuring Well-Being, OECD Publishing, Paris, 2011.

[16] OECD, How's Life in Your Region? Measuring Regional and Local Well-being for Policy Makers, OECD Publishing. http://www.oecd-ilibrary.org/docserver/download/0414031e. pdf?expires $=1444402894 \&$ id $=\mathrm{id} \&$ accname $=$ ocid $47012051 \&$ checksum=25DAE94984CCA66088F3E1B56F856D57. Accessed on 4 May 2016, 2014.

[17] D. Osborn, A. Cutter and F. Ullah, Universal sustainable development goals, Understanding the Transformational Challenges for Developed Countries. Report of a study by stakeholder forum, May 2015. https://sustainabledevelopment.un. org/content/documents/1684SF_-_SDG_Universality_ 
Report_-_May_2015.pdf. Accessed on 4 May 2016, 2015.

[18] E. Saluveer and R. Ahas, Presentation for the EFGSconference 2010 in Tallinn, Estland. http://www.efgs.info/wpcontent/uploads/conferences/efgs/2010/29_Mobile_telephonesand-mobile-positioning-data-as-source-for-populationstatistics_-Erki-Saluveer-et-al.pdf Accessed on 4 May 2016, 2010.

[19] B. Schmidt et al., Entlastungen spürbarer machen - Wie wird der Kontakt zur Verwaltung wahrgenommen? WISTA Wirtschaft und Statistik, 2/2015, Statistisches Bundesamt, Wiesbaden, 2015.

[20] S. Schnorr-Bäcker, Zukunft von Indikatorensystemen in der amtlichen Statistik. Statistisches Bundesamt: Wissenschaftliches Kolloquium 2007, 1-8. http://kolloq.destatis. de/2007/schnorr-baecker.pdf. Accessed on 4 May 2016, 2007.

[21] S. Schnorr-Bäcker and H. Bömermann, Regional statistical data on measuring progress, The OECD approach "Howąrs Life? - Measuring Well-Being", Journal of Official Statistics Berlin Brandenburg 2/2013, 2013.

[22] S. Schnorr-Bäcker, Common issues on benefits and challenges of Big Data sources. Presentation for the UNSD and NBS China International Conference on Big Data for Official Statistics, 28. - 30.10.2014 in Beijing, China. http://unstats. un.org/unsd/trade/events/2014/beijing/presentations/day3/ morning/3.\%20Pane1\%20Discussion,\%20Common\%20issues -Susanne\%20Schnorr-Baecker.pdf. Accessed on 11 May 2016, 2014.

[23] S. Schnorr-Bäcker, Regional statistical data for Germany, Europe and the world, Statistical Journal of the IAOS 32(4) (2016), 515-535.

[24] J.E. Stiglitz, A. Sen and J.-P. Fitoussi, Report by the Commission on the Measurement of Economic Performance and Social Progress, Paris. http://www.insee.fr/fr/publications-etservices/dossiers_web/stiglitz/doc-commission/RAPPORT_ anglais.pdf. Accessed on 4 May 2016, 2009.
[25] M. Tiru, Overview of the sources and challenges of mobile positioning data for statistics, http://unstats.un.org/unsd/trade/ events/2014/Beijing/Margus\%20Tiru\%20-\%20Mobile\%20 Positioning\%20Data\%20Paper.pdf. Accessed on 4 May 2016, 2014.

[26] United Nations, A new global partnership: Eradicate poverty and transform economies through sustainable development. Report of the High-Level Panel of Eminent Persons on the Post-2015 Development Agenda, New York. http://www.post2015hlp.org/wp-content/uploads/2013/05/ UN-Report.pdf. Accessed on 4 May 2016, 2013.

[27] UN General Assembly, Transforming our world: the 2030 Agenda for Sustainable Development, A/70/L.1, New York, 18 September 2015. http://www.un.org/ga/search/view_doc. asp?symbol=A/70/L.1\&Lang=E. Accessed on 4 May 2016, 2015.

[28] UN Economic and Social Council, Report of the friends of the Chair Group on broader measures of progress, February 2015. E/CN.3/2015/2, 8, 2015

[29] UN Statistical Commission, Some national, regional and international efforts and practices in the measurement of sustainable development and human well-being. Room document for the $44^{\text {th }}$ Meeting of the United Nations Statistical Commission. http://unstats.un.org/unsd/statcom/doc14/BG-FOCBroader $\% 20$ measures-Practices $\% 20$ on $\% 20$ broader $\% 20$ meas ures\%20of\%20progress.pdf. Accessed on 4 May 2016, 2014.

[30] A. van Donkelaar, R.V. Martin, M. Brauer and B.L. Boys, Use of Satellite Observations for Long-Term Exposure Assessment of Global Concentrations of Fine Particulate Matter, Environmental Health Perspectives 123(2) (February 2015), 135-143.

[31] A. Wirthmann, Big Data at Eurostat and the ESS, Presentation for the NTTS 2015, Workshop on Big Data, 9 Mar 2015, Brussels, 2015 